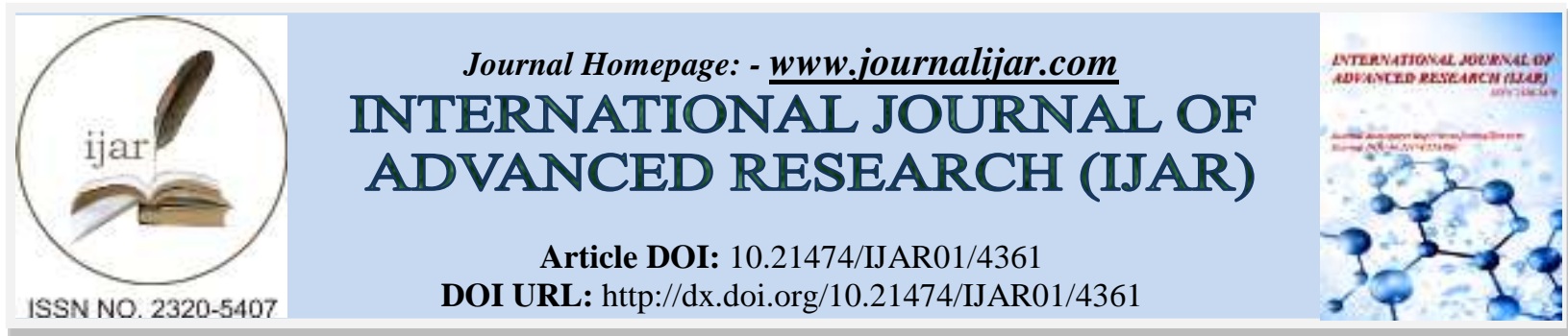

RESEARCH ARTICLE

\title{
PATTERN OF DRUG USE AMONG FEMALE DRUG USERS IN KABUL, BALKH AND NANGARHAR
} PROVINCIES.

Abdul Rahman Laiq.

Jodhpur School of Public Health (JSPH) Maulana Azad University Jodhpur, India.

\section{Manuscript Info}

Manuscript History

Received: 29 March 2017

Final Accepted: 25 April 2017

Published: May 2017

Key words:-

Preconception Health care, Knowledge,

Risk behavior, chronic conditions.

\section{Abstract}

Drug use is prevalent throughout Afghanistan with the highest drug use occurring in rural villages. Approximately 2.9 to 3.6 million Afghans could test positive for one or more drugs and 1.0 to 1.2 million of them are children. Of this total, approximately 1.9 to 2.4 million adults and 90,000 to 110,000 children could be drug users. (INL report 2015). Opioids are the most prevalent class of drugs in Afghanistan. Opioids use is significantly higher in rural villages than in the urban centers. It is used in nearly one out of five Afghan households (19\%). Opioids were detected in one quarter $(25 \%)$ of all rural households and the rate is more than four times higher than among urban households (6\%). Approximately $7 \%$ of the population tested positive for Opioids with the rural rate approximately three times higher: 9\% rural Compared to 3\% urban. Approximately 6\% of children tested positive for Opioids. The percentage of rural children who tested positive for Opioids is approximately six times higher: $1.3 \%$ urban compared to $7.5 \%$ rural. (INL 2015 report).

Nearly one million Afghans (between 15 and 64 years) (6.6\% of total population) are estimated to be regular and / or problem drug users. This includes 110,000 female drug users. The numbers of heroin users have increased from 50,000 to 120,000, since 2005 constituting a grand leap of 140 per cent (UNODC, Afghanistan Drug Use Survey, 2009). Almost $6 \%$ of all drug users had injected at least once in their lifetime (IBID). Only a small fraction (11\%) of drug using Respondents reported they had received any support, intervention, or treatment for their drug use (IBID).

\section{Objectives of the Study:-}

- To find out main types of drugs used by female drug users visiting three drop-in-centers.

- To recommend key intervention strategies, including scaling-up current interventions in Afghanistan

\section{Research Methodology:-}

- Cross sectional quantitative research. The geographical area for implementation of questionnaire is the Drop in centers in three provinces. Each of these drop-in-centers is providing services to almost 30 female drug users on regular basis per/week. In view 
of this, the researcher selected a sample size of 30 female drug users to be interviewed per drop-in-center in each province (Balkh, Kabul and Nangarhar provinces).

Conclusion and Recommendations:-

- Amongst this study, opium drugs were regular, frequent and heavy. Injecting drug use was most common in Kabul and Nangarhar and Majority of the FDUs were illiterate.

- Conducting further research to know more about FDUs in all provinces of Afghanistan. Provision of services to the partner and children of FDUs and addressing stigma and discrimination.

Copy Right, IJAR, 2016,. All rights reserved.

\section{Introduction:-}

Acknowledgment:-

All glory is to Allah Almighty, The Superior and The Sovereign, who enabled me to undertake study on pattern of drug use among female drug users visiting Drop-in-Centers in Kabul, Nangarhar and Balkh Provinces.

Firstly, I would like to express my sincere gratitude to UNODC colleagues Dr. Raza Stanikzai, and Dr. Nasir Ahmad Safi for the continuous support of my MPH study and related research, for their patience, motivation, and immense knowledge.

Beside my colleagues, I am extremely thankful and indebted to my professors at Jodhpur School of Public Health (JSPH), Maulana Azad University, Dr Latika Nath Sinha, Dr Nitin Joshi, Dr Pramila Vivek, for sharing their expertise, sincere and valuable guidance and encouragement extended to me during this period. I could not have imagined having a better tutor than them to complete my assignment.

I thank the staff of FHO (Family Health Organization) for their time assistance in data collection without their support it would not have been possible.

I am also grateful to my site supervisor Dr. Nasir Ahmad Safi Project Coordinator of Drug Demand Project in UNODC for his always support during this research.

Last but not the least, I would like to thank my family for supporting me spiritually throughout my studies and writing this thesis and my life in general.

\section{Chapter 1: Introduction:- \\ Drug Use:-}

Drug use is prevalent throughout Afghanistan with the highest drug use occurring in rural villages. Approximately 2.9 to 3.6 million Afghans could test positive for one or more drugs and 1.0 to 1.2 million of them are children. Of this total, approximately 1.9 to 2.4 million adults and 90,000 to 110,000 children could be drug users. (INL report 2015).

Opioids are the most prevalent class of drugs in Afghanistan. Opioids use is significantly higher in rural villages than in the urban centers. It is used in nearly one out of five Afghan households (19\%). Opioids were detected in one quarter $(25 \%)$ of all rural households and the rate is more than four times higher than among urban households $(6 \%)$. Approximately $7 \%$ of the population tested positive for Opioids with the rural rate approximately three times higher: 9\% rural compared to 3\% urban. Approximately 6\% of children tested positive for Opioids. The percentage of rural children who tested positive for Opioids is approximately six times higher: $1.3 \%$ urban compared to $7.5 \%$ rural. (INL 2015 report).

Nearly one million Afghans (between 15 and 64 years) (6.6\% of total population) are estimated to be regular and / or problem drug users. This includes 110,000 female drug users. The numbers of heroin users have increased from 50,000 to 120,000 , since 2005 constituting a grand leap of 140 per cent (UNODC, Afghanistan Drug Use Survey, 
2009). Almost $6 \%$ of all drug users had injected at least once in their lifetime (IBID). Only a small fraction (11\%) of drug using respondents reported they had received any support, intervention, or treatment for their drug use (IBID).

\section{Study Rationale:-}

Drug use is considered as deviant behavior and drug users are stigmatized in many countries including Afghanistan. When women use drugs the stigma and subsequent social isolation is even more severe than when compared to male drug users. In Afghanistan, women often have lesser education, poorer access to health services and do not enjoy parity with men in terms of employment as well as other privileges. Use of drugs further weakens their socially disadvantaged position and increases her vulnerability further. Lack of information about issues related to women in general and drug users in particular necessitated the present study.

The Afghanistan Drug Use Survey, 2009 indicates some data on the pattern of drug use among drug users and female drug users on a regional basis in Afghanistan. However the data as it relates to female drug use is limited.

The result of this study attempts to fill in this data gap by providing further information to policy and decision makers on the patterns of drug use on a provincial basis. This will help them to better design policies and programs as well as to allocate and relocate future resources accordingly. This research will recommend key interventions as per the pattern of drug use in each city.

\section{Operational Definitions:-}

For the purpose of the study, the following agreed upon definitions between the various stakeholders were used:

1. Female Drug Users (FDUs): Women who are 18 years or older and visiting drop-in-centers in Kabul, Nangarhar and Balkh provinces, who has used any sort of drugs for non-therapeutic purposes in the last 12 months and last 30 days (regular drug users).

2. Female Injecting Drug Users (FIDU): Female Drug Users (FDUs) who had injected drugs at least once in the past one month for other than medical reasons.

\section{Research Objectives:-}

- $\quad$ To find out main types of drugs used by female drug users visiting three drop-in-centers.

- To recommend key intervention strategies, including scaling-up current interventions in Afghanistan.

\section{Research Gaps:-}

A cross sectional survey method has been used for this study. A total of 90 female drug users were selected purposively (female drug users visiting drop-in-centers) in three provinces of Afghanistan. The study covers only a fraction of female drug users who were visiting female drop-in-centers and therefore there is an in-built bias in the sample selections. So the research is not representative of all female drug users in Afghanistan. As the data is collected from a small sample of the female drug users who use the services in the drop-in-centers, therefore the result of the study cannot be generalized to all female drug users in Afghanistan. However, the aims to provide an insight into the pattern of female drug use based on which further research can be conducted.

\section{Chapter 2: Literature Review:- Intro para:-}

2.1 Definition The literature review defines the medically approved definition of drug abuse, dependence and psychoactive substance. This is the criteria that will be followed in this research study. The second set of literature reviewed examines the current information on female drug use in Afghanistan. The current research will add to this limited information on female drug users.

"Dependence is a syndrome characterized by compulsive use of a substance despite knowledge of the negative consequences of such use (WHO, 2008, p. 6).

Psychoactive substances are those, when ingested/inhaled/injected, affects mental processes, e.g. cognition or affect (IBID).

2.2 Afghan situation Afghanistan is the world's largest producer of opium, 5800 metric tons of opium are produce in 2011 (Afghanistan Opium Survey, 2011). Over 90 per cent of the world's heroin is manufactured from opium produced in Afghanistan (World Drug Report, 2010, 2011). 
Drug use is prevalent throughout Afghanistan with the highest drug use occurring in rural villages. Approximately 2.9 to 3.6 million Afghans could test positive for one or more drugs and 1.0 to 1.2 million of them are children. Of this total, approximately 1.9 to 2.4 million adults and 90,000 to 110,000 children could be drug users. (INL report 2015).

Opioids are the most prevalent class of drugs in Afghanistan. Opioids use is significantly higher in rural villages than in the urban centers. It is used in nearly one out of five Afghan households (19\%). Opioids were detected in one quarter $(25 \%)$ of all rural households and the rate is more than four times higher than among urban households (6\%). Approximately $7 \%$ of the population tested positive for Opioids with the rural rate approximately three times higher: $9 \%$ rural compared to $3 \%$ urban. Approximately $6 \%$ of children tested positive for Opioids. The percentage of rural children who tested positive for Opioids is approximately six times higher: $1.3 \%$ urban compared to $7.5 \%$ rural. (INL 2015 report).

In terms of patterns of drug use among female drug users there is some limited data available. The National Drug Use Survey carried out in 2005 by UNODC found that psychotropic substances were used more by male drug users compared with female drug users (Macdonald, 2008). The estimated 180,000 psychotropic drug users cited in the survey, 50 percent were men, 30 percent women, and the rest children. However it is noted that because of the social and cultural position of women in Afghanistan, this population may have been more difficult to access by surveyors and therefore possibly constitute a larger, if hidden population of psychotropic drug users than men (IBID).

According to the report of an NGO responsible for coordinating drug treatment services in Gardez (Paktia province), 70 percent of female clients attending community-based drug treatment services using psychotropic substances, while 15 percent take opium and 13 percent take hashish. In another outreach treatment service in Kandahar, 40 percent of female clients take psychotropic substances, while 50 percent take opium, 4 percent take hashish, and 4 percent take heroin .By contrast, an outreach programme for female problem drug users in Kabul estimated that 30 percent of its clients used only psychotropic substances, while a number of the 70 percent of clients that used opium also used psychotropic substances. In all of these studies, the primary reason for taking psychotropics was as a medicine to help cope with the problems of daily life (IBID).

Recreational and social use of opium has been a traditional habit in Afghanistan (Todd et al, 2007)

In study conducted by Afghanistan Independent Human Rights Commission in February 2008 on Effective Factors Associated with Drug Addiction and the Consequences of Addiction on Afghan women in 21 provinces of Afghanistan found that $65.2 \%$ of 828 interviewed female drug users were married. Monthly income of the $67.6 \%$ of the interviewed female drug users were less than 3,000 Afs (Effective Factors Associated with Drug Addiction and the Consequences of Addiction on Afghan women, 2008). Opium was the most common drug used by female (83. $2 \%$ ), followed by heroin (7.8\%), marijuana (6.2\%) and other types of drugs such as morphine (2.6\%) (IBID).

Qualitative work to date indicates that some factors driving transition from smoking to injecting may be modified, such as peer pressure and police harassment, allowing transition back to less risky routes of drug consumption (Todd C. , 2006-2007).

In terms of HIV prevalence, there is no data available for female drug users. However among male injecting drug users, the average HIV prevalence was 7\% in three cities (Herat, Kabul and Mazar) in 2009 as compared to $3 \%$ in one city (Kabul) in 2006 (Integrated Bio Behavioural Surveillance in Afghanistan, 2010). There are estimates that around 1,000-2,000 people may be living with HIV in Afghanistan (UNAIDS/WHO, 2011. All over Afghanistan there could be between 1,000- 2,000 individuals living with HIV (UNAIDS/WHO, 2011). The HIV Epidemic is at an early stage, but increasing in Afghanistan and is concentrated among high-risk groups, mainly injecting drug users (World Bank, 2011).In another study conducted in 2007 among IDUs in Kabul, the result revealed that $3 \%$ of IDUs were infected with HIV, 6.5\% with HBV and 36.6 with HCV (Todd et al, 2007).

2.3 regional patterns though there is some information on pattern of drug use among female drug users from Pakistan. As the study conducted by UNODC Pakistan reveals that majority of the FDUs were illiterate; $66 \%$ of the interviewed female drug users did not receive any formal schooling (Female Drug Use in Pakistan, 2010). Almost $60 \%$ of interviewed female drug users were married (IBID). 
Hashish was the common drug used by FDUs interviewed. As 58\% of the interviewed drug users reported using it ever and also in the last six months. $42 \%$ reported that they had used it in the last month as well. Pharmaceutical drugs were the next drugs of choice followed by Heroin and Bhang (IBID).

The same study conducted by the on pattern of drug use among female drug users in India reveals that majority of the female drug users were in the productive age-group, 67\% had been using drugs regularly for more than 5 years (Women and Drug Abuse, the problem in India, 2002). Current drug used was primarily heroin followed by alcohol and cannabis (IBID).

On pattern of drug use among female drug users, another study in India in 2008 reveals following figures; Female drug users had high rates of lifetime use of tobacco (79.1\%), alcohol (77.4\%), heroin (33.5\%), dextropropoxyphene (25.9\%), sleeping pills (22.4\%) and cannabis (22.7\%) (Murthy, 2008).

2.4 Other factors (biological, structural)The intersection of unsafe injecting drug use and unsafe sexual practice is the main factor in the increased risk for HIV infection of the injecting drug users (HIV/AIDS prevention and care for female injecting drug users, 2006). Female injecting drug users differ from their male counterparts in terms of their background, their reasons for using drugs, and their psychosocial needs. However, most HIV/AIDS prevention and care programs are not reaching this vulnerable group because services are designed for men (IBID). Female drug users are facing a lot of barriers accessing drug treatment services, as lack of staff knowledge around the specific needs of female drug users and, lack of gender appropriate services, judgmental of the staff, stigma and discrimination imposed by staff members, and costs of the services (Anna Roberts, 2010). Structural barriers stem from issues around the functioning of treatment services and include; lack of child-care, unsafe or indiscreet locations, rigid service schedules, long waits, bureaucratic hurdles, and lack of sufficient services provisions (IBID). In response to the huge drug use problem in Afghanistan, there are only 40 structured drug treatment services across 21 provinces which mostly provide low intensity support, usually based on residential and home-based approaches. Only $11 \%$ of drug users reported receiving any kind of treatment for their drug problem yet more than $90 \%$ of drug users expressed a desire for help (Leslie, 2011). Concluding para

\section{Chapter 3: Methodology:-}

\section{Study Design Overview:-}

A cross sectional study method is used for this study. A total of 90 female drug users were selected purposively (female drug users visiting drop-in-centers) in three provinces of Afghanistan.

\section{Data Collection Techniques:- Measures/Inventory:-}

The female social workers in drop-in-centers collected responses from the clients by personal or impersonal means after they had been trained by principle investigator. Respondents were given choices while answering the questions. Following questionnaires are used for data collection:

\section{Sample:-}

Non-probability (purposive) method of sampling was used for selecting respondents for the interview. Each of these drop-in-centers is providing services to almost 30 female drug users on regular basis per/week. In view of this, the researcher selected a sample size of 30 female drug users to be interviewed per drop-in-center in each province (Balkh, Kabul and Nangarhar provinces).

\section{Sample Characteristics:-}

A total of 90 drug users were interviewed in three provinces. The criteria for sample selection included; women who were 18 years or older; using the services of the drop-in-centres in Kabul, Nangarhar and Balkh provinces; who has used any sort of drugs for non-therapeutic purposes in the last 12 months and last 30 days (regular drug users). Only those women who met the selection criteria were included in the study.

Mean age of the clients interviewed were 39 years. 
Table1:- Sample frequency.

\begin{tabular}{|c|c|c|}
\hline \multicolumn{2}{|c|}{ Provinces } \\
\hline Kabul & Frequency & Percent \\
\hline Nangarhar & 30 & 33.3 \\
\hline Balkh & 30 & 33.3 \\
\hline Total & 30 & 33.3 \\
\hline
\end{tabular}

Table 2:- Age.

\begin{tabular}{|c|c|c|c|}
\hline \multicolumn{3}{|c|}{ Statistics } \\
\hline Valid & Age in Years (n=90) & Provinces \\
\hline \multirow{2}{*}{$\mathrm{N}$} & Missing & 90 & 90 \\
\hline & Mean & 0 & 0 \\
\hline Median & 39.13 & \\
\hline Mode & 40.00 & \\
\hline Minimum & 35 & \\
\hline Maximum & 18 & \\
\hline
\end{tabular}

Table 12 :- Characteristics of the sample of female drug users selected for the survey.

Data Collection Instruments:-

Data were collected by trained interviewers using a structured questionnaire which was designed in English, subsequently translated into Dari; the Dari versions were used to collect the required data. The question included questions on socio-demographic and personal characteristics, as well as drug using practices (types of drugs used/injected, drug use in group/sharing) and availability of health services and their utilization. Did you pre-test the questionnaire - if so, mention it's here. Else say, that the instrument was based on pre-tested instrument used in the UNODC Drug report etc. (See Annex XX).

\section{Data Analysis:-}

Code sheets were developed in line with the codes in the questionnaire. The data was entered and analyzed through SPSS version 16.

\section{Consent and ethical Considerations:-}

This study cannot be the representative of all Afghanistan, therefore, it did not require Institutional Review Board (IRB) approval. However, for ethical purpose all data are stored in a safe place and only authorized staff have access to the data bank. The individual information of respondent is kept confidential and not disclosed during the analysis or dissemination phases.

The study was conducted with full in compliance with human rights standards (How? Explain?)

Consent was sought from respondents after informing them of the objectives of the study and they were assured of confidentiality at each phase of the study. During data collection, justice was ensured which means an equal importance to every participant in the study. If any of the respondents was uncomfortable in answering some questions the interviewers stopped at that moment without making an effort to keeps the interview going on.

\section{Chapter 4: Analysis:-}

\section{Socio-Demographic Information:-}

Age:-

The mean age of the female drug users who were interviewed was reported to be 39 years (median 40) years). The maximum number of (45.6\%) of the drug users were between 18 to 40 years of age, which is the active reproductive age. 


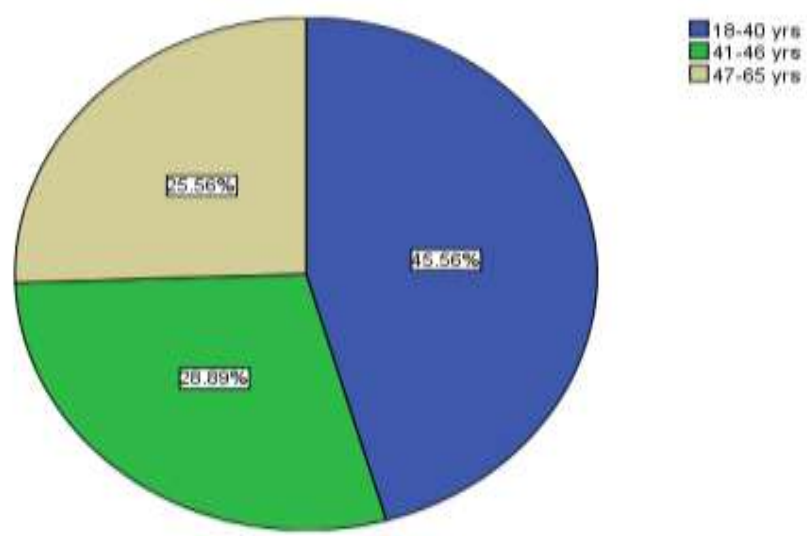

\section{Educational Status:-}

Figure 1:- Age distribution of FDUs interviewed.

Majority of the FDUs interviewed were illiterate. Nearly $96 \%$ of the FDUs interviewed had not received any formal education. Only $1.1 \%$ of the respondents had received schooling up to the primary level and only $3.3 \%$ of the respondent had high level education. The education levels among female drug users from Nangrahar was higher than the other two provinces.
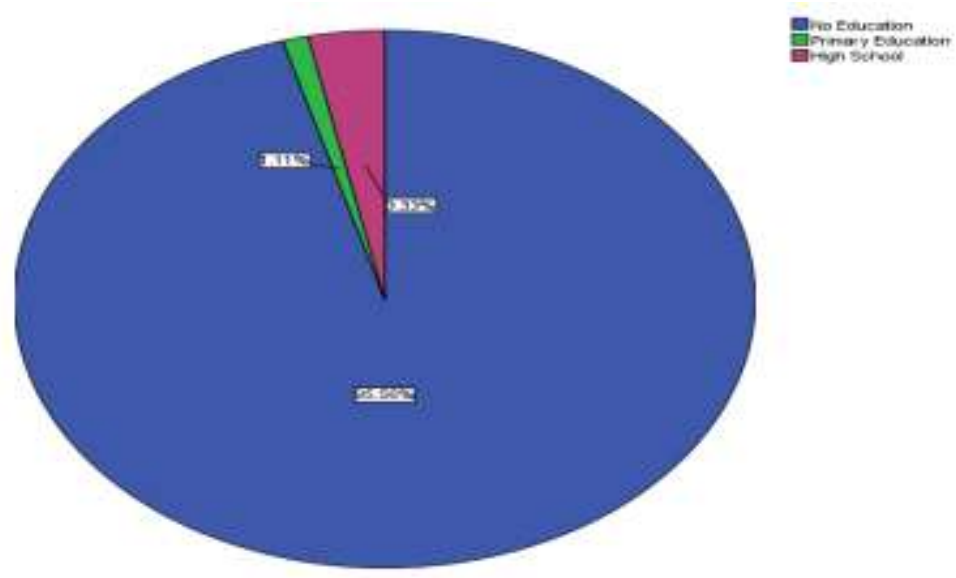

Figure 2:- Education level of FDUs interviewed.

Table 3:- Education Level of FDUs per Province.

\begin{tabular}{|c|c|c|c|c|c|}
\hline \multicolumn{9}{|c|}{ Provinces } \\
\hline \multirow{3}{*}{ Education Level } & No Education & Kabul & Nangarhar & Balkh & Total \\
\cline { 2 - 6 } & Primary Education & 29 & 28 & 29 & 86 \\
\cline { 2 - 6 } & High School & 1 & 0 & 1 & 1 \\
\hline & Total & 30 & 30 & 30 & 90 \\
\hline
\end{tabular}

\section{Marital Status/Number of Children:-}

Majority of the female drug users were married $(82 \%)$. Nearly $8 \%$ of the interviewed females were never married, while $10 \%$ reported to be widowed. This indicates a need to also reach out to male partners of female drug users with HIV prevention and care services. 


\section{Marital Status of FDUs}

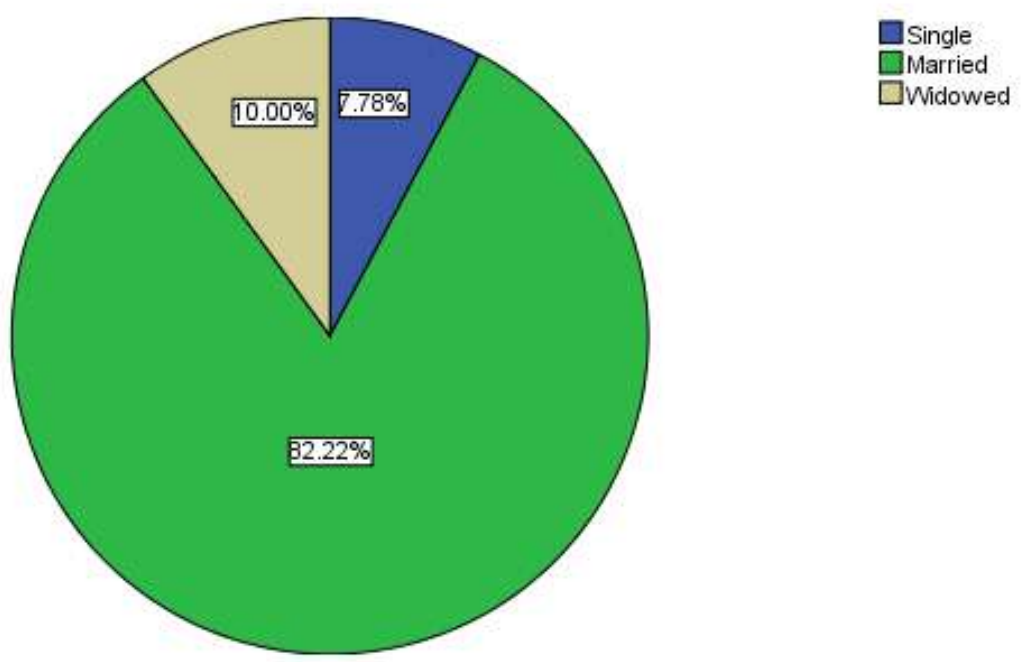

Figure 3:- Marital status of FDUs.

In Kabul, $90 \%$ of female drug users were married and $10 \%$ were widowed. Drug use among unmarried women in Kabul was not documented. 13\% of FDUs in Nangarhar were single and 10\% were widowed. In Balkh 10\% of FDUs never married and $10 \%$ of the FDUs reported to be widowed.

Table 4:- Marital Status of Female Drug Users Per Province.

\begin{tabular}{|c|c|c|c|c|c|}
\hline & & Single & Married & Widowed & Total \\
\hline \multirow{3}{*}{ Provinces } & Kabul & 0 & 27 & 3 & 30 \\
\cline { 2 - 6 } & Nangarhar & 4 & 23 & 3 & 30 \\
\cline { 2 - 6 } & Balkh & 3 & 24 & 3 & 30 \\
\hline \multicolumn{2}{|c|}{ Total } & 7 & 74 & 9 & 90 \\
\hline
\end{tabular}

On an average each female drug users had more than 4.4 children. Almost $41 \%$ of the subjects interviewed had 1-4 children, were almost $36 \%$ interviewed FDUs had 5-8 children and 11\% had 9-11 children. Drug use by the among females could have negative consequences for their the children.

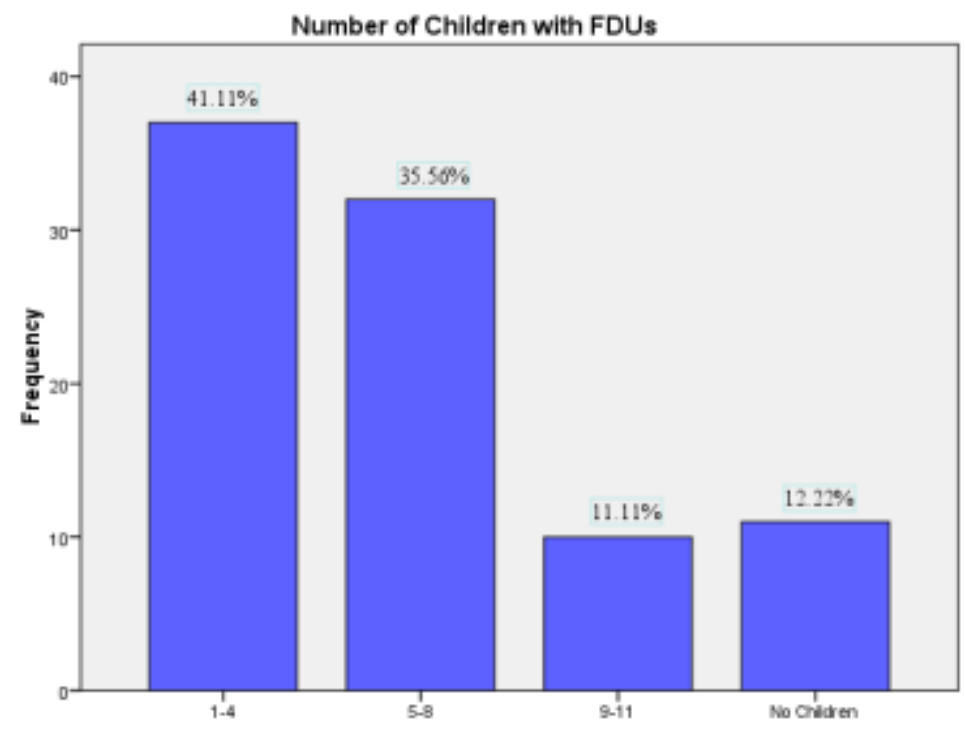

Figure 4:- Number of Children with FDUs. 


\section{Occupation and Income:-}

Analysis conducted to look at the various professions that FDUs are involved with showed interesting results. The maximum numbers $(83 \%)$ were housewives and were not attached to any profession with almost zero income per month. Only $17 \%$ of the interviewed female drug users had jobs. Among the $17 \%$ of the employed female drug users, $53 \%$ were employed fulltime and $47 \%$ were part-time employees with different entities. The average income of these FDUs who had a job was 5,600 Afghani per month.

Table 5:- Employment of FDUs.

\begin{tabular}{|c|c|c|}
\hline \multicolumn{2}{|c|}{ Employment } \\
\hline & Frequency & Percent \\
\hline No & 75 & 83.3 \\
\hline Yes & 15 & 16.7 \\
\hline Total & 90 & 100.0 \\
\hline
\end{tabular}

$30 \%$ of FDUs interviewed in Kabul was employed. This may be due to high education of female drug users in Kabul, openness of the community to female workers and availability of the job opportunity. In comparison employment levels in other provinces were much lower (7\% in Nangarhar and none in Balkh).

CAN'T SAY “ IN Balkh almost 100\% of the female drug users were jobless and housewives BECAUSE ON 24 MARRIED - SO MAYBE THE OTEHRS ARE NOT HOUSEWIVES."

\section{Employment of FDUs Per Province}

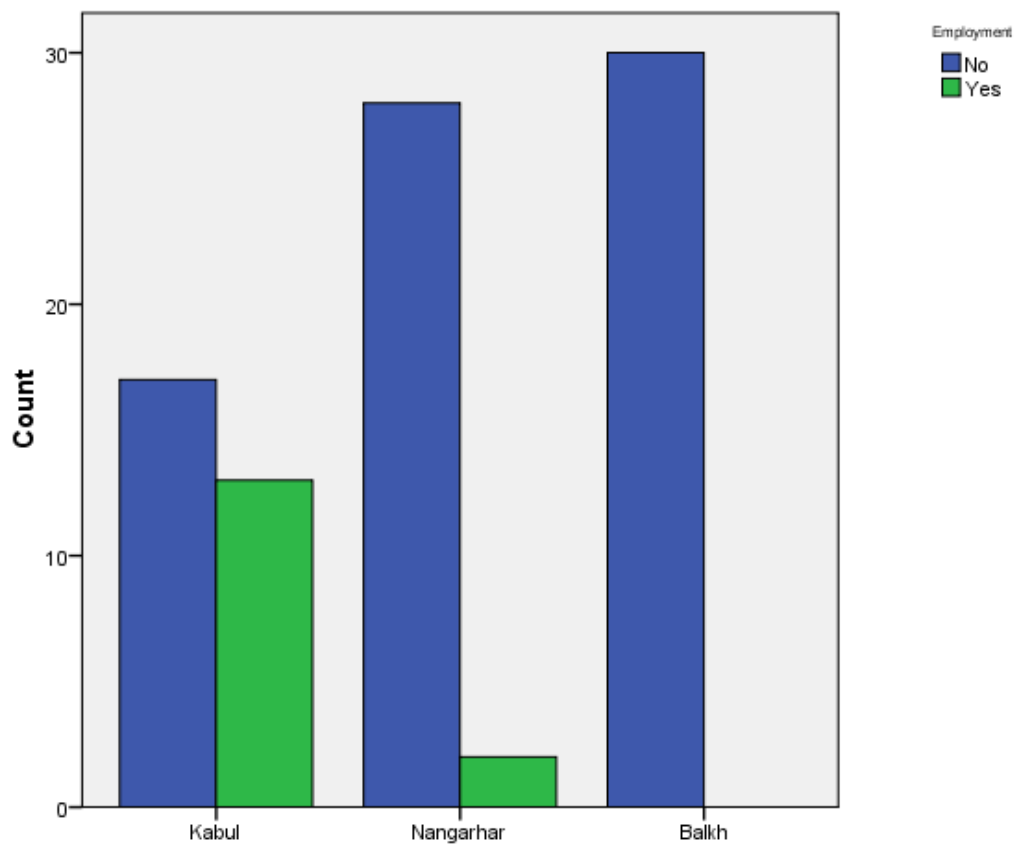

Figure 5:- Employment of FDUs per province.

83\% of the FDUs had no income, 8.8\% had income of 4000-6000 Afs in month, 4.4\% had income of 7000-9000 Afs and $3.3 \%$ on interviewed drug users had income of 1000-3000 Afs in month. 


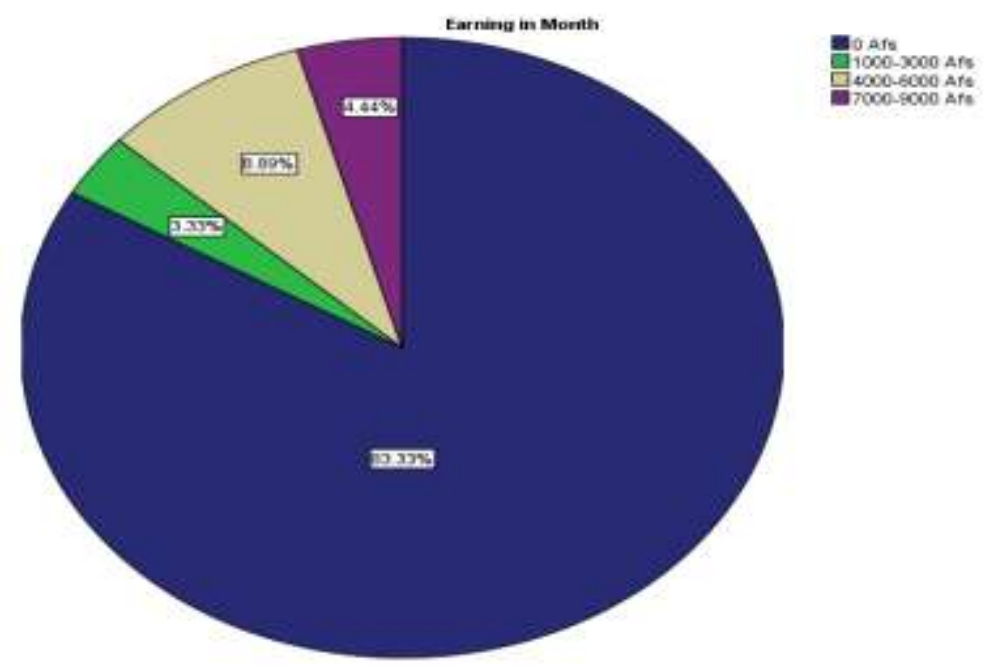

Figure 6:- Earning of the interviewed FDUs in month.

\section{Migration/Mobility Status of the Female Drug Users:-}

In response to the question of countries lived in past 12 months, almost all (97\%) respondents said that they were living in Afghanistan. When compared with figures available for male drug users it is interesting to note that a majority of the male drug users reported living outside Afghanistan in last 12 months, mainly in Iran and Pakistan (PUT SOURCE). But in this study only 4\% of the female drug users reported living outside Afghanistan in last 12 months.

Table 6: FDUs lived outside Afghanistan in past 12 months

\begin{tabular}{|c|c|c|}
\hline & Frequency & Percent \\
\hline Not lived & 86 & 95.6 \\
\hline Pakistan & 4 & 4.4 \\
\hline Total & 90 & 100.0 \\
\hline
\end{tabular}

The country which they reported living was Pakistan. All female drug users who reported living outside Afghanistan in past 12 months were from Balkh province of Afghanistan.

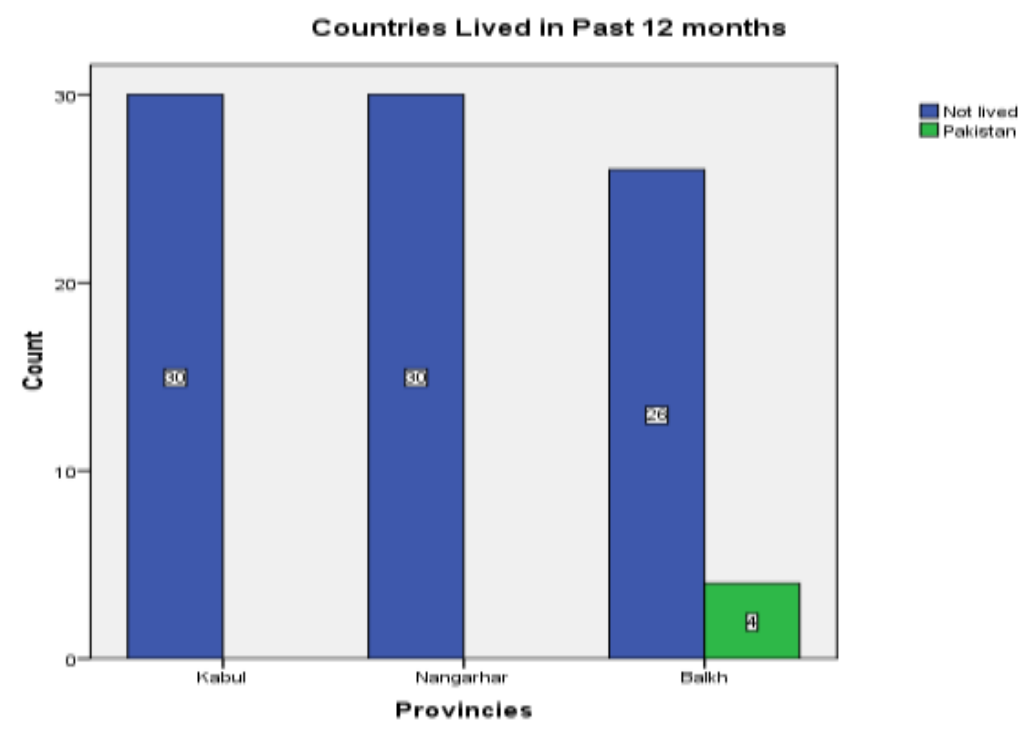

Figure 7:- Countries FDUs lived in past 12 months per province. 


\section{Types of Drugs Used:-}

The analysis was further extended to evaluate the types of drugs used by female drug users. We collected information on drug use in the past 12 months and regular use of the drug in the last month. The drugs for which the information was collected included Opium, Heroin, Hashish, Alcohol, Opiate painkillers (Pentazocine, Tremadol) and Pharmaceutical drugs. This group included various Antihistamines and Benzodiazepines.

As Table 7 shows, opium was the most commonly used drug by FDUs. Nearly three fourths (73\%) of the interviewed drug users reported using opium on regular basis. Heroin was the second most common drug used by the female drug users who were interviewed (16\%), followed by benzodiazepines (Diazepam, Alprazolam etc.) (7.8 $\%)$. Small proportions of female drug users reported using opiate pain killers $(2.2 \%)$ and antihistamines (1.1\%). As reported earlier, the majority of the female drug users were in reproductive age.

The minimum age for the initiation of the drug use was reported as early as 3 years from Balkh. This could be related to the practice of traditional opium use to calm children which is common. The maximum age of initiating drug use was reported at 52 years. The overall mean age of drug initiation in all provinces was recorded as 28.8 years.

Table 7:- Drug Used by FDUs in three provinces.

\begin{tabular}{|c|c|c|c|}
\hline \multicolumn{4}{|c|}{ Type of Drugs Used by Female Drug Users Interviewed } \\
\hline \multirow{3}{*}{$\begin{array}{c}\text { Kabul, Nangarhar and Balkh } \\
\text { Provinces }\end{array}$} & Sleeping Pills & Frequency & Percent \\
\cline { 2 - 4 } & Opium & 7 & 7.8 \\
\cline { 2 - 4 } & Heroin & 66 & 73.3 \\
\cline { 2 - 4 } & Opiate Pain Killers & 2 & 15.6 \\
\cline { 2 - 4 } & Antihistamines & 1 & 2.2 \\
\cline { 2 - 4 } & Total & 90 & 1.1 \\
\cline { 2 - 4 } & \multicolumn{2}{c}{} \\
\hline
\end{tabular}

The pattern of drug use was different in each province. In Kabul the majority of the female drug users were using opium followed by heroin and opiate painkillers. In Nangarhar, almost all types of drugs were used by female drug users including antihistamines. On other hand, in Balkh almost 100\% of the female drug users were opium users. This could be related to the traditional use of opium among different communities in the Northern provinces. Therefore that traditional use of opium may have led to some of the female drug users getting dependent on opium.

Poly drug use was also common among the female drug users interviewed, especially use of benzodiazepines with opium .None of the respondents reported using alcohol or hashish.

\section{Types of Drug Used by FDUs in each Province}

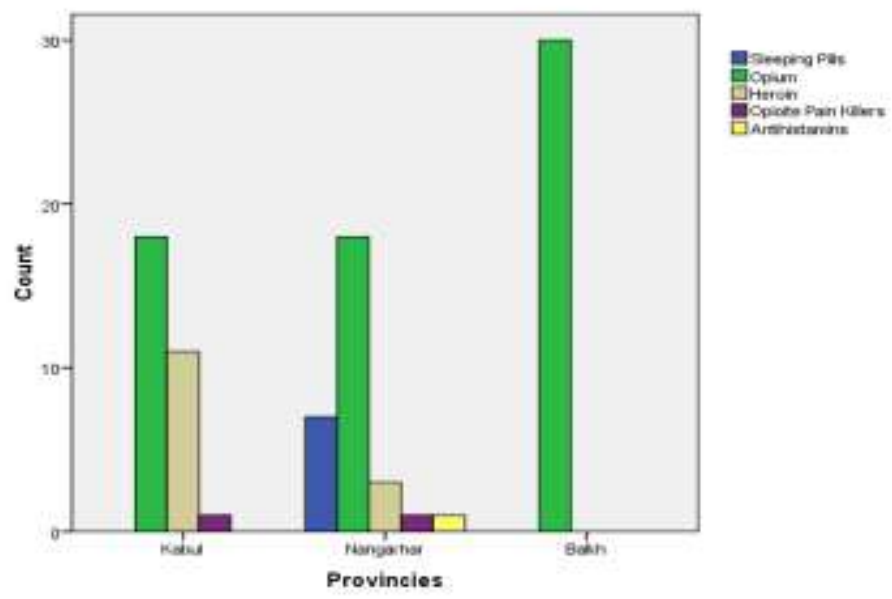

Figure 8:- Types of drug used by FDUs in each province. 


\section{Mode of Drug Use:-}

The majority of respondents reported using drugs orally $(81 \%)$. Among oral users opium followed by benzodiazepine tablets were the most common used drugs. A significant proportion of the respondents were injecting drug users (10\%). Only $1.1 \%$ of the interviewed female drug users reported smoking as their mode of drug use. Around $7.8 \%$ of the respondents were using drugs through multiple modes including smoking, oral and injection.

Almost 8\% (6 clients) of the 7 subjects reported using drugs through multiple routes. One of the modes of drug use was injecting. This will bring the total number of injecting drug users interviewed in this study to 15 subjects; which is $17 \%$ of the total sample.

The Table below is indicative of the mode and types drug use by FDUs.

Table 8:- Type and mode of drug used by FDUs.

\begin{tabular}{|l|l|l|l|l|l|l|l|}
\hline Mode of Use & Hashish & $\begin{array}{l}\text { Sleeping } \\
\text { Pills }\end{array}$ & Opium & Heroin & $\begin{array}{l}\text { Opiate Pain } \\
\text { Killers }\end{array}$ & Alcohol & Antihistamines \\
\hline & Count & Count & Count & Count & Count & Count & Count \\
\hline Smoking & 0 & 0 & 0 & 1 & 0 & 0 & 0 \\
\hline Oral & 0 & 7 & 66 & 0 & 0 & 0 & 0 \\
\hline Sniffing & 0 & 0 & 0 & 0 & 0 & 0 & 0 \\
\hline Injecting & 0 & 0 & 0 & 6 & 2 & 0 & 1 \\
\hline Multiple Modes & 0 & 0 & 0 & 7 & 0 & 0 & 0 \\
\hline
\end{tabular}

Heroin was the most common drug used through smoking by female drug users. Opium and sleeping pills were used by the respondents orally. Sniffing as a mode of drug use was not reported among female drug users interviewed.

Heroin, opiate pain killers (Pentazocine) and antihistamines were the drugs mostly injected by FDUs interviewed. A majority of the female drug users administered heroin through multiple modes; injection and smoking.

Drug use mode was different in different provinces, as in Kabul the respondent were using drugs mainly by oral followed by inhalation, injection and multiple modes and the same patterns were observed in Nangarhar province. But in Balkh province almost $100 \%$ of the respondents were oral drug users.

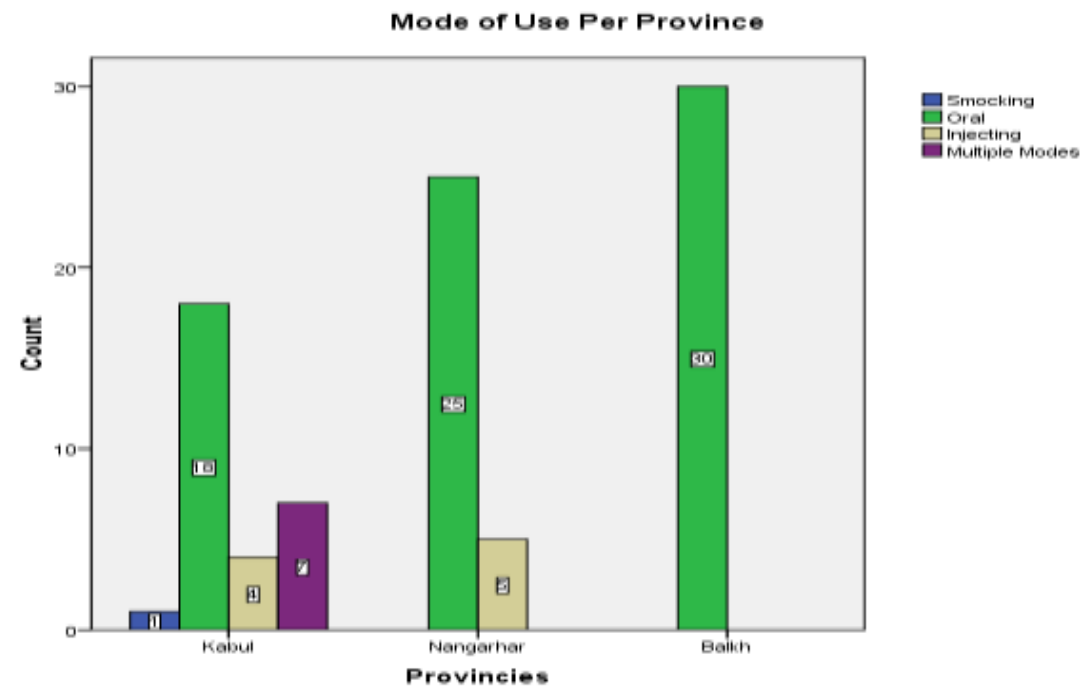

Figure 9:- Mode of drug use per province.

\section{Frequency of Drug Use:-}

A majority (87\%) of the respondents were using drugs every day, $11 \%$ were using it at least once a week and $2 \%$ of the drug users were using drugs less than once a week. This reflects that most respondents were regular drug users. 
Table 9:- Use of drug by FDUs in past month (every day, at least once or less than once a week)

\begin{tabular}{|l|l|l|l|l|l|l|l|}
\hline & Hashish & $\begin{array}{l}\text { Sleeping } \\
\text { Pills }\end{array}$ & Opium & Heroin & $\begin{array}{l}\text { Opiate Pain } \\
\text { Killers }\end{array}$ & Alcohol & Antihistamines \\
\hline & Count & Count & Count & Count & Count & Count & Count \\
\hline Every Day & 0 & 7 & 55 & 14 & 1 & 0 & 1 \\
\hline At least once a week & 0 & 0 & 9 & 0 & 1 & 0 & 0 \\
\hline less than once a week & 0 & 0 & 2 & 0 & 0 & 0 & 0 \\
\hline
\end{tabular}

\section{Injecting Drug Use:-}

Of the 90 subjects interviewed, only 15 (17\%) reported that they injected drugs during the last 12 months. Further analysis revealed that injection drug use was only found in Kabul and Nangarhar provinces. The mean age for the first injection among female drug users was 30.5 years.

A majority of the female injecting drug users were injecting heroin (80\%), almost $14 \%$ were injecting opiate painkillers in particular Sosegon and 6\% were injecting antihistamines (Avil).

Table 10:- Mode of Drug Use per Province.

\begin{tabular}{|c|c|c|c|c|c|c|}
\hline \multicolumn{2}{|c|}{ Mode of Use } \\
\hline & & Smoking & Oral & Sniffing & Injecting & Multiple Modes \\
\hline \multirow{3}{*}{ Provinces } & & Count & Count & Count & Count & Count \\
\cline { 2 - 7 } & Kabul & 1 & 18 & 0 & 4 & 7 \\
\cline { 2 - 7 } & Nangarhar & 0 & 25 & 0 & 5 & 0 \\
\hline
\end{tabular}

\section{Drug using partner:-}

A majority $82.2 \%$ of the female drug users interviewed was using drugs alone and $17.8 \%$ of them reported using drugs with their partner. Use of drugs in group among female drug users interviewed was not documented. (THIS SHOULD BE MOVED UP. NOT PART OF IDU SECTION).

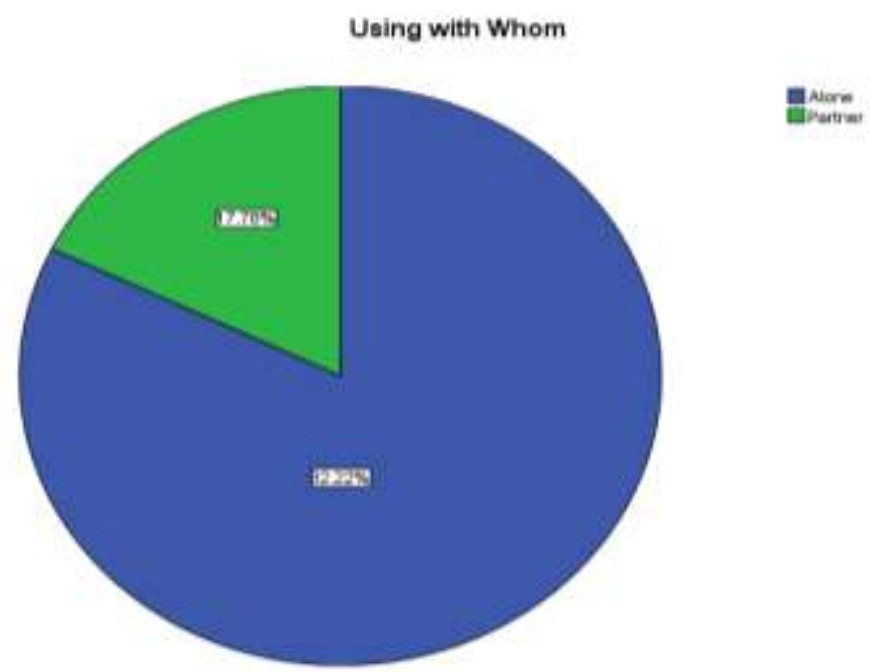

Figure 10:- Risk behavior among FIDUs.

However, among female drug users, $73 \%$ of the female injecting drug users were using drugs with their partner. So we can conclude that the partners of FIDUs partners are also injecting drugs. In order to decrease the harm through injecting drugs, services should be provided to both male and female injecting drug users. Over a fourth of the FIDUs (27\%) were injecting alone. 
Table 11:- Type of drug and using with.

\begin{tabular}{|c|c|c|c|c|c|c|}
\hline \multicolumn{9}{|c|}{ Mode of Use } \\
\hline & & Smocking & Oral & Sniffing & Injecting & Multiple Modes \\
\hline & & Count & Count & Count & Count & Count \\
\hline \multirow{3}{*}{ Using with Whom } & Alone & 0 & 69 & 0 & 4 & 1 \\
\cline { 2 - 8 } & Partner & 1 & 4 & 0 & 5 & 6 \\
\cline { 2 - 8 } & Group & 0 & 0 & 0 & 0 & 0 \\
\hline
\end{tabular}

Almost $57 \%$ of female drug users in Kabul were using drugs alone and $43 \%$ were using drugs with their partner. $90 \%$ of female drug users in Nangarhar were using drugs alone and $10 \%$ were using it with their partner. As majority of the female drug users in Balkh were opium users, so therefore almost $100 \%$ of respondents in mentioned province were using drugs alone. Table:

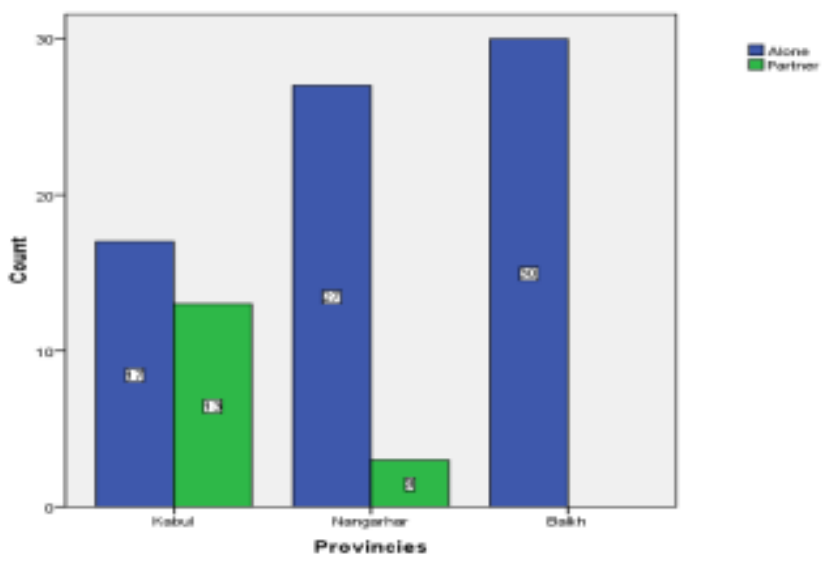

Figure 11:- Risky behavior per province.

$20 \%$ of FIDUs reported sharing their needles/syringes with their regular partner. Response to sharing of injecting equipment with causal partner and group was zero in all provinces.

$20 \%$ of FIDUs in Kabul and Nangarhar provinces had history of borrowing/landing needles/syringes from the regular partner. The findings also reveal that $93.3 \%$ of FIDUs used disposable syringes last time they injected and the $6.6 \%$ of the respondents boiled needle/syringes.

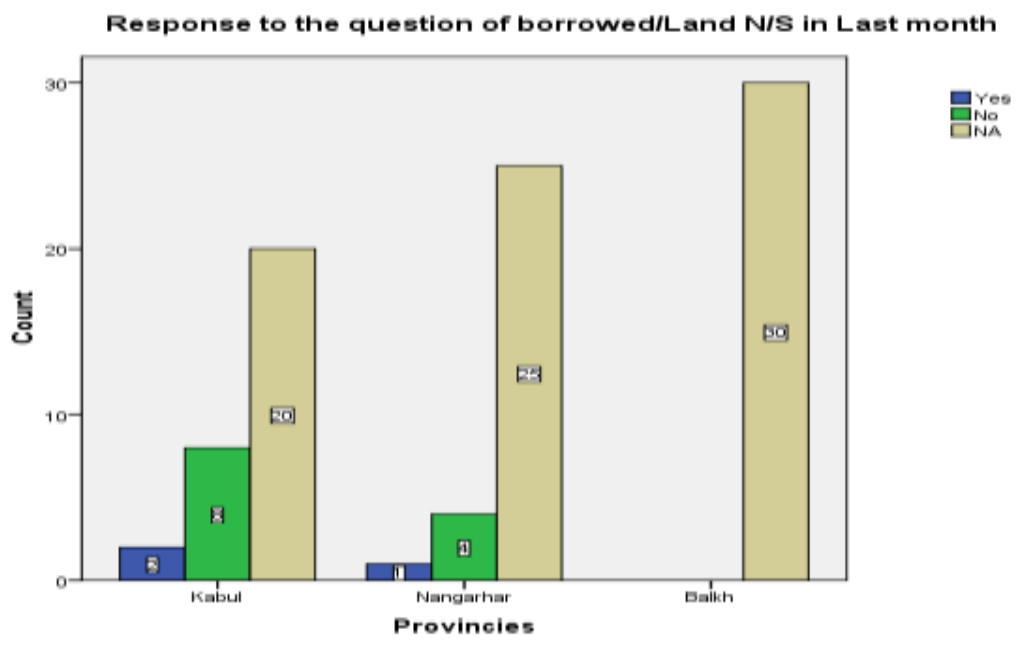

Figure 12:- Sharing N/S per provinces. 


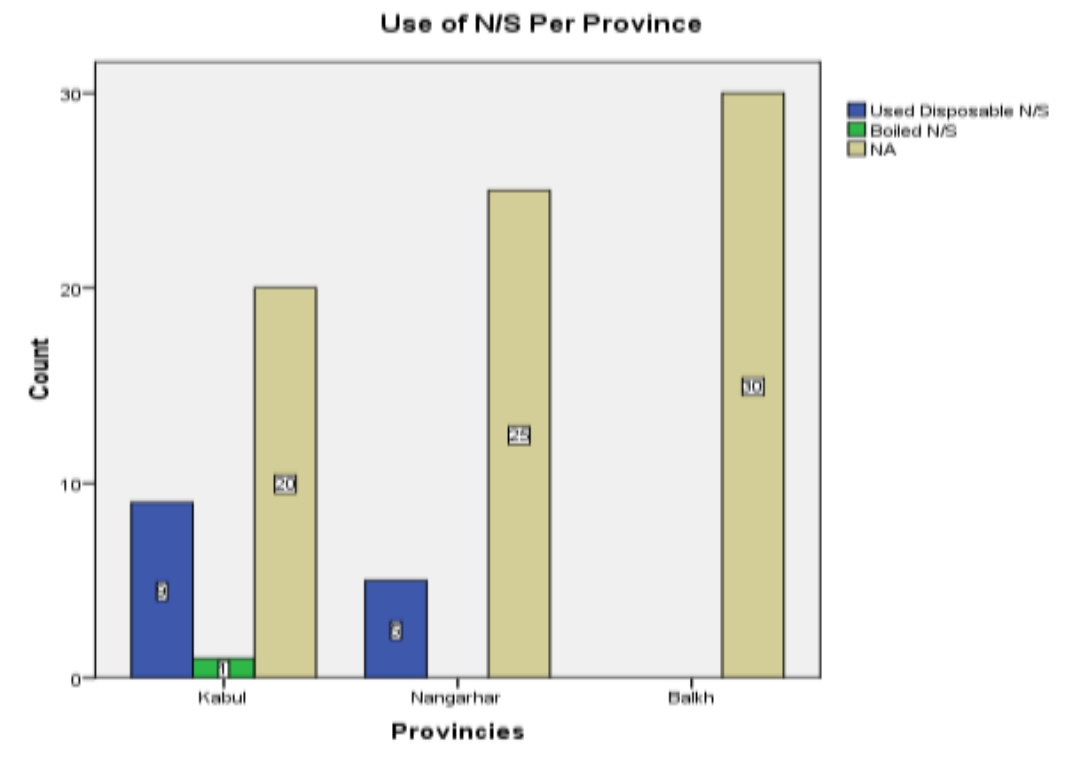

Figure 13:- Use of N/S last time injected per provinces.

\section{Family Reaction to Drug Use:-}

Family member of majority of the FDUs were aware of the drug used by their female family member. As $94.4 \%$ of the respondents said yes to this question.

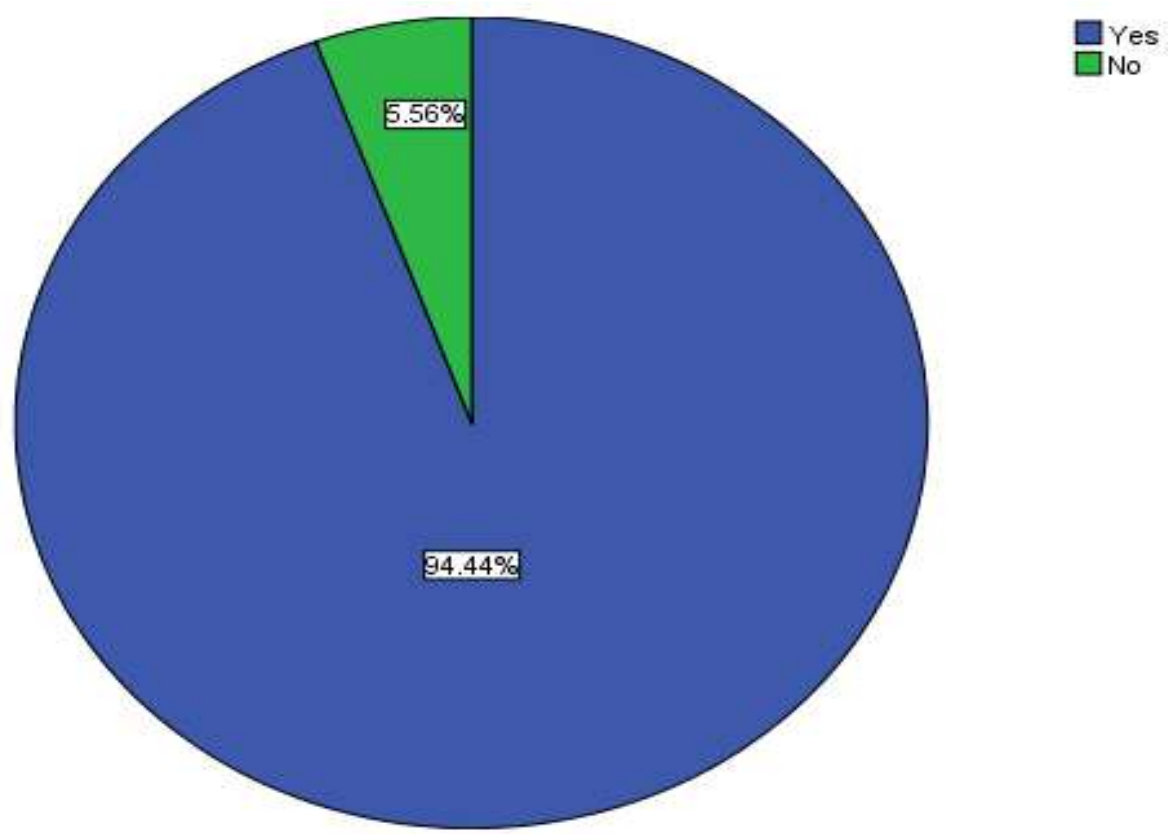

Figure 14:- Family knows about the drug use of their family member.

In regards to the reaction of the family to the drug use of the female, $66.6 \%$ of the female drug users responded that their families are unconcern to the use of the drugs. $22.2 \%$ of the FDUs responded that their family members are hostile to their drug using act. $11.1 \%$ reported that their family members are supportive; especially this is on those cases where the partner is also drug user. $1.1 \%$ of the FDUs said that they are without family member at home. 
Table 12: Family Reaction To the drug use of FDUs

\begin{tabular}{|c|c|c|c|}
\hline \multicolumn{2}{|c|}{ Reaction of family } \\
\hline & Frequency & Percent & Valid Percent \\
\hline Supportive & 10 & 11.1 & 22.2 \\
\hline Hostile & 20 & 22.2 & 65.6 \\
\hline Unconcern & 59 & 65.6 & 1.1 \\
\hline No Family & 1 & 1.1 & 100.0 \\
\hline Total & 90 & 100.0 & 1.0 \\
\hline
\end{tabular}

Family reaction to the drug use of FDUs in Kabul was mix (supportive, hostile and unconcern) but in other two provinces (Nangarhar and Balkh) majority of the families were unconcern to the drug use of their female family member.

Table:

\section{Family reaction to drug use per province}

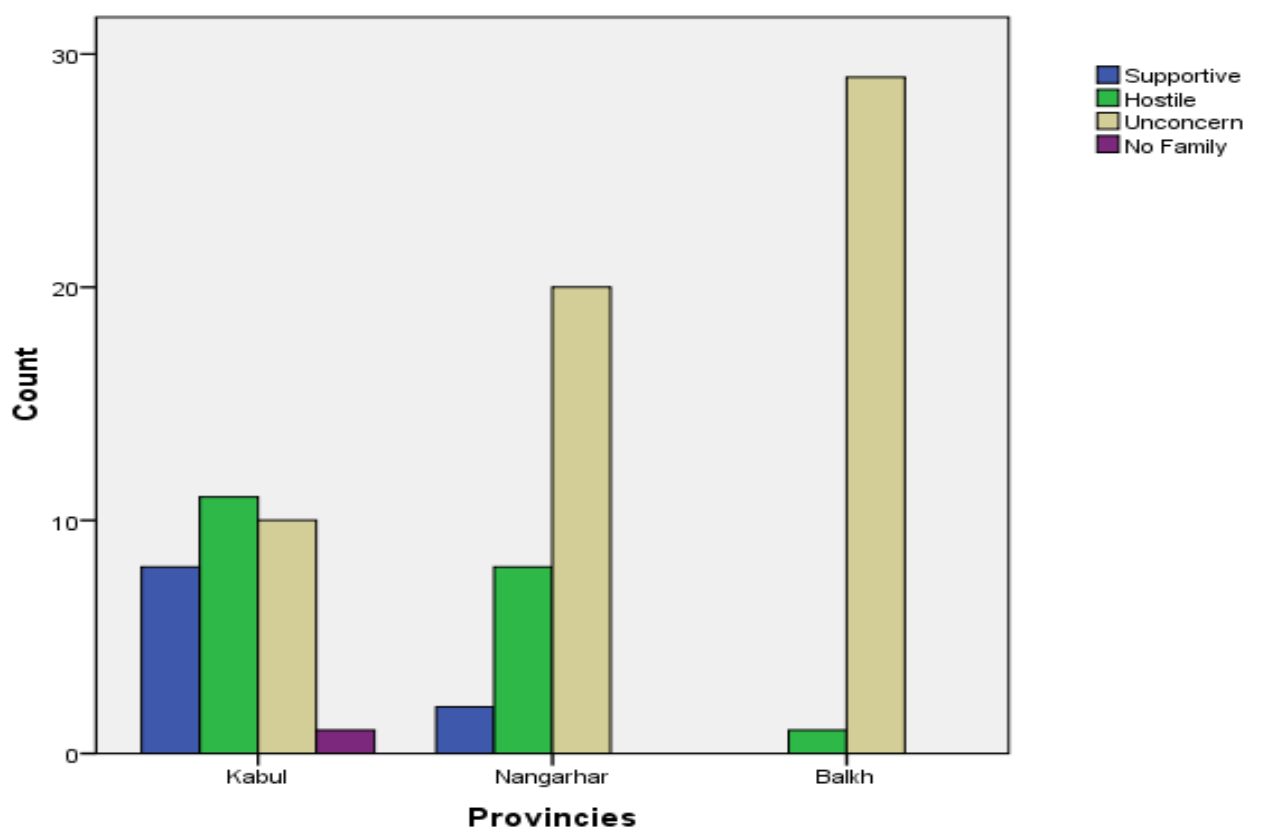

Figure 15:- Family reaction per province.

\section{Services to Female Drug Users:-}

Almost $100 \%$ of the services are delivered by NGOs. $68.9 \%$ of the respondents received counseling and health education services. $15.6 \%$ received counseling with home based detoxification services and $15.6 \%$ received health education, individual, group and family counseling, detoxification and treatment for their physical problems from the health centers. Detoxification of the female drug use was very common in Kabul in comparison to Nangarhar and Balkh provinces. 


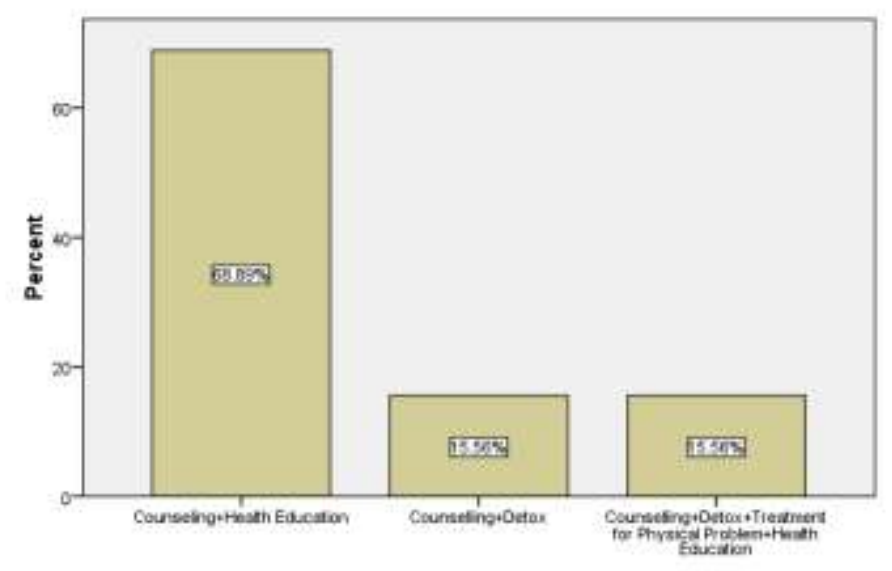

Figure 16:- Services FDUs received.

\section{Chapter 5: Conclusion:-}

\section{Conclusion:-}

- Amongst this study, opium drugs were regular, frequent and heavy.

- Pattern of drug use was different among FDUs in three provinces.

- Injecting drug use was most common in Kabul and Nangarhar.

- Majority of the FDUs in Balkh were oral drug users.

- Majority of FDUs were in reproductive age group.

- FDUs were accompanied by their children, risk and impact of drugs may be high on the children living with their addicted mother.

- Injecting drug use was present among FDUs with high risk behavior.

- Sharing of needle/syringes was documented among the regular partners of the FIDUs.

- Majority of the FDUs were illiterate.

- Majority of the female drug users were jobless.

- Use of pharmaceutical and heroine was documented among FDUs.

- Majority of family member were aware of their female family member drug use and mainly their reactions to the drug use their family member was unconcern.

- Majority of the FIDUs were using disposable needle and syringes.

- Female Drug users mainly had access to health education, counseling and detoxification services.

- Female Drug users were mainly using NGOs as the point of contact to their addiction.

Future Implications/Future Research Direction:-

- Conducting further research to improve understanding of female drug use in all Afghanistan

- Provision of services to the partner of FDUs

- Provision of drug treatment services to FDUs

- Services to the children of the FDUs.

- Stigma and discrimination should be addressed

- Job opportunities and Education programs should be provided to FDUs 


\section{Bibliography:-}

1. (2015) INL Afghanistan National Drug Survey

2. (2014), World drug report, United Nations Office on Drugs and Crime

3. (2015), Afghanistan Drug report, United Nations Office on drugs and Crime

4. (2010). Afghanistan Opium Survey. United Nation Office on Drugs and Crime.

5. Anna Roberts, B. M. (2010). Women who inject drugs, A review of their risks, experiences and needs. UNODC.

6. Bank, W. (2011). HIV/AIDS in Afghanistan. World Bank.

7. (2008). Effective Factors Associated with Drug Addiction and the Consequences of Addiction on Afghan women. Wardak, Ghazni, Paktia, Nangarhar, Laghman, Kunar, Badakhshan, Takhar, Kondoz and Balkh: Afghanistan Independent Human Rights Commission.

8. Emran, R., Afarin, M., \& Kaveh, G. T. (2005). Qualitative study of injecting drug users. Tehran, Iran.

9. (2010). Female Drug Use in Pakistan. UNODC, Pakistan.

10. HIV/AIDS prevention and care for female injecting drug users. (2006). UNODC.

11. (2010). Integrated Biologic, and Behavioural Surveillance in Afghanistan. Kabul, Afghanistan: Johns Hopkins University,Bloomberg School of Public Health.

12. Johns Hopkins, U. (2010). Integrated Biologic, and Behavioural Surveillance in Afghanistan. Kabul, Afghanistan.

13. Leslie, D. T. (2011). Assessment of the HIV/drug use situation and mapping of available care \& treatment services among returnees/deportees in Afghanistan. UNODC.

14. Macdonald, D. (2008). Afghanistan's Hidden Drug Problem: The Misuse of Psychotropics.

15. Murthy, D. P. (2008). Women and Drug Abuse in India, The SWAHA Study ((Substance, Women and Highrisk Assessment Study). UNODC, Regional Office for South Asia.

16. Pratima, D. (2008). Substance, Women, and high risk assessment in India. India.

17. (2011). PROFILE, DRUG USE PATTERN, RISK BEHAVIOR AND SELECTED BIO - MARKERS OF WOMEN DRUG USERS FROM SEVEN SITES IN NEPAL. Nepal: UNODC.

18. Todd et al, A. A. (2007). HIV, Hepatitis C, and Hepatitis B Infections and Associated Risk Behiviour in Injecting Drug Users in Kabul.

19. Todd, C. (2006-2007). A qualitative assessment of injection drug use and harm reduction programmes in Kabul, Afghanistan.

20. Todd, C. (2005). Drug use and harm reduction in Afghanistan.

21. UNAIDS. (2008). Terminology Guidelines. Kabul: UNAIDS.

22. UNAIDS/WHO. (2011). UNAIDS and WHO HIV Epidemilology Update .

23. UNODC. (2005). Afghanistan Drug Use Survey. United Nations Office on Drugs and Crime

24. WHO. (2008). Operational guidelines for the management of opioid dependence in SEAR. World Health Organization.

25. William Byrd, C. W. (2004). Drugs and Development in Afghanistan. The World Bank.

26. (2002). Women and Drug Abuse, the problem in India. United Nations International Drug Control Programme,Regional Office for South Asia (UNDCP -ROSA).

27. (2010,2011). World Drug Report. Vienna: UNODC. 